thất trái. Tình trạng căng thành (wall stress) và dãn thất trái có thể làm thay đổi thuộc tính điên sinh lý của cơ tim, gọi là điều hòa ngược cơ điện học dẫn tới kéo dài thời kỳ tái cực và thời gian điện thế hoạt động. John (2004), yếu tố tiên lượng mạnh mẽ nhất về nguy cơ RLN thất sau phẫu thuật là chức năng thất trái giảm. Chúng tôi đánh giá đặc điểm RLN tim (bảng 5 và bảng 6) cho thấy không có sự khác biệt giữa đặc điểm RLN tim với RLVĐ vùng và $\mathrm{EF}$ thấp trước phẫu thuật. Điều này cũng phù hợp với các nghiên cứu cho thây đây là những yểu tố nguy cơ RLN tim sau phẫu thuật.

\section{KẾT LUÂ̂N}

Trước phẫu thuật CNCV, rối loạn nhịp tim là tình trạng thường gặp trong đó RLN trên thất có tỉ lệ khá cao 89,9\%, RLN thất có tỉ lệ $60,5 \%$.

Sau phẫu thuật CNCV số lượng và mức độ RLN thất tăng do ảnh hưởng cấp tính của cuộc phẫu thuật, sau 3 tháng và 6 tháng ổn định và giảm. RLN trên thất ít bị ảnh hưởng của cuộc phẫu thuật, rung nhĩ mới xuất hiện sau phẩu thuật CNCV tăng theo thời gian.

\section{TÀI LIÊU THAM KHẢO}

1. Mosorin, M.A., et al (2015), "Five-Year Outcome after Coronary Artery Bypass Surgery in Survivors of Out-of-Hospital Cardiac Arrest", Front Surg. 2: pp. 2.

2. Thoren, E., et al (2014), "Postoperative atrial fibrillation predicts cause-specific late mortality after coronary surgery", Scand Cardiovasc $\mathrm{J}$, 48(2): pp. 71-8.

3. Hata, M., et al (2013), "Does warfarin help prevent ischemic stroke in patients presenting with post coronary bypass paroxysmal atrial fibrillation?", Ann Thorac Cardiovasc Surg. 19(3): pp. 207-11.

4. Sezai, A. and M. Shiono (2013), Atrial fibrillation after coronary artery bypass grafting", Gen Thorac Cardiovasc Surg. 61(8): pp. 427-8.

5. Sadr-Ameli, M.A., et al (2013), "Ventricular tachyarrhythmia after coronary bypass surgery: incidence and outcome", Asian Cardiovasc Thorac Ann. 21(5): pp. 551-7.

6. El-Chami, M.F., et al (2012), "Ventricular Arrhythmia After Cardiac Surgery: Incidence, Predictors, and Outcomes", Journal of the American College of Cardiology. 60(25): pp. 2664-2671.

7. Thomas H Lee (2005), "Guidelines for Ambulatory ECG and electrophysiological testing", Heart disease. A textbook of Cardiovascular Medicine. pp. 757 - 766.

\title{
ĐẶC ĐIỂM HÌNH ẢNH ĐộNG MẠCH PHẾ QUẢN TRÊN CHỤP MẠCH MDCT Ở BÊ̂NH NHÂN HO RA MÁU DO LAO PHỔI
}

\section{TÓM TÁ́T}

Mục tiêu: Nghiên cứu đặc điểm hình ảnh động mạch phế quản trên chụp mạch MDCT ở bệnh nhân ho ra máu do lao phổi. Đối tượng và phương pháp nghiên cứu: Nghiên cứu tiến cứu trên 22 bênh nhân ho ra máu do lao phổi tại Trung tâm Hô hấp, Bệnh viên Quân y 103 và Khoa Lao Hô hấp, Bênh viến Phổi Trung ương từ tháng 9/2019 đến tháng 10/2020. Kết quả: Chụp mạch MDCT phát hiện được 58 động mach thủ phạm, tỷ lệ phù hợp với chụp và gây tắc động mach phế quản là $96,7 \%$. Bênh nhân có 2 động mach thủ phạm chiếm tỷ lệ cao nhất $(36,4 \%)$, số độ̉ng mạch trung bình trên mỗi bệnh nhân là 2,4 $\pm 1,2$. Đường kính dao động từ 2,1-5,1mm, trung bình 2,8 $-3,3 \mathrm{~mm}$. Không có trường hợp nào gặp tai biến, biến chứng nguy hiểm. Kết luận: Chụp mạch MDCT ở bệnh nhân ho ra máu do lao phổi là kỹ thuật an toàn, tỷ lệ phát hiện động mạch thư phạm cao.

\footnotetext{
${ }^{1}$ Trung tâm Nội Hô hấp, Bệnh viện Quân y 103 ²Bênh viện Quân y 103

Chịu trách nhiệm chính: Lê Văn Nam

Email: drlenam103@gmail.com

Ngày nhận bài: 6.01.2021

Ngày phản biên khoa hoc: 4.3.2021

Ngày duyệt bài: 12.3.2021
}

\section{Lê Hữu Ý ${ }^{1}$, Lê Văn Nam²}

Từ khoá: Ho ra máu, chụp mạch MDCT, động mạch phế quản, lao phổi.

\section{SUMMARY \\ FEATURES OF MULTIDETECTOR CT \\ BRONCHIAL ARTERIOGRAPHY IN TUBERCULOUS HEMOTYSIS PATIENTS}

Objectives: To study bronchial artery characteristics on MDCT angiography in hemoptysis patients caused by pulmonary tuberculosis. Methods: It was a prospective study which included 22 hemoptysis patients caused by pulmonary tuberculosis at Respiratory Center, Military Hospital 103 and Pulmonary Tuberculosis Department, Vietnam National Lung Hospital from September 2019 to October 2020. Results: 58 culprit arteries were detected by MDCT angiography, and the suitability between MDCT angiography and bronchial artery embolization was $96.7 \%$. The rate of patients with 2 culprit arteries was the highest $(36.4 \%)$, and the number of culprit artery per patient was $2.4 \pm 1.2$. The mean diameter was 2.8 - $3.3 \mathrm{~mm}$ with range $2.1-5.1 \mathrm{~mm}$. There were no patients experienced severe complications. Conclusion: MDCT angiography was safe for hemoptysis patients caused by pulmonary tuberculosis and the accuracy of MDCT angiography in the identification of culprit arteries was high. 
Keywords: Hemoptysis, MDCT angiography, bronchial artery, pulmonary tuberculosis.

\section{I. Đă̆T VẤN ĐỀ}

Ho ra máu được định nghĩa là tình trạng ho và khạc ra máu, máu chảy ra từ nhu mô phổi hoặc đường thở dưới. Đây là một cấp cứu nội khoa thường gặp, có thể đe doạ tính mạng. Các nguyên nhân thường gặp nhất là lao phổi, giãn phế quản, u nấm phổi, nhiễm trùng hô hấp và ung thư phổi. Trong đó, lao phổi và di chứng sau lao vẫn là các nguyên nhân chính dẫn đến ho ra máu và cần phải điều trị bằng gây tắc mạch phế quản, đặc biệt ở các nước có gánh nặng bệnh lao cao như Viêt Nam [1].

Ỡ những bệnh nhân ho ra máu, việc xác định nguồn gốc và nguyên nhân bằng các biện pháp không xâm lấn trước khi tiên hành các kỹ thuật can thiệp đóng vai trò rất quan trọng. Vào năm 2005, Yoon và CS. đã nghiên cứu đồ chính xác của kỹ thuật chụp cắt lớp vi tính (CT- Computed Tomography) đợn dãy trong việc dự đoán sự hiện diện của động mạch hệ thống không thuộc hệ phể quản ở bệnh nhân ho ra máu mức độ nặng và đến nay, đã có nhiều nghiên cứu chứng minh chụp mạch MDCT (Multi Detector Computed Tomography) trước khi gây tắc động mạch phễ quản đóng một vai trò quan trọng trong phát hiện động mạch thủ phạm và chẩn đoán nguyên nhân ho máu [2]. Tuy nhiên, hầu hết các nghiên cứu đều là hồi cứu và nghiên cứu trên bênh nhân lao phổi còn han chể. Do đó, mục tiêu của nghiên cứu này là đánh giá khả năng phát hiện và đặc điểm hình ảnh động mạch phế quản trên chụp mạch MDCT ở bệnh nhân ho ra máu do lao phổi.

\section{II. ĐỐI TƯợNG VÀ PHƯƠNG PHÁP NGHIÊN CỨU}

1. Đối tượng nghiên cứu. Tất cả bệnh nhân ho ra máu có chỉ định chụp mạch MDCT và gây tắc động mạch phế quản trong thời gian điều trị tại Bệnh viện Quân y 103 và Bệnh viện Phối Trung ương từ tháng 9/2019 đễn tháng 10/2020.

Tiêu chuẩn lưa chon: Bênh nhân được chẩn đoán xác định ho ra máu dựa vào lâm sàng, hình ảnh Xquang, nội soi phế quản và loại trừ các bệnh nhân chảy máu đường hô hấp trên và xuất huyết tiêu hoá. Chẩn đoán xác định lao phổi dựa vào lâm sàng, hình ảnh Xquang gợi ý, soi AFB đờm hoăcc Xpert MTB (+).

Tiêu chuẩn loại trư: Bệnh nhân có chống chỉ định chụp mạch MDCT và gây tắc động mạch phế quản.

\section{Phương pháp nghiên cứu}

- Thiết kế nghiên cứu: Nghiên cứu tiến cứu, mô tả cắt ngang. Các bệnh nhân đều được chụp mạch MDCT và gây tắc động mạch phế quản.

- Quy trình chụp mạch MDCT: Thực hiện bằng máy cắt lớp vi tính 64 dãy (SOMATOM Sensation 64, Đức) tại Bệnh viện Phổi Trung ương và 16 dãy (Brilliance 16, Hoa Kỳ) tại Bệnh viện Quân y 103. Toàn bộ bệnh nhân được chụp tử đỉnh phổi đến hết vòm hoành ở tư thế nằm ngửa. Bệnh nhân được tiêm vào tĩnh mạch cánh tay khoảng 80 đến 100 mL Omnipaque, sau đó là $50 \mathrm{~mL}$ nước muối sinh lý với tốc độ $4 \mathrm{~mL} / \mathrm{s}$ bằng máy tiêm tự động. Sử dụng chương trình phân mềm kích hoạt bolus tự động, với điểm tỷ trọng cân xác định là vị trí vùng đoạn xuống động mạch chủ ngực, ngay dưới carina. Khi tỷ trọng đạt được $100 \mathrm{HU}$, việc thu thập dữ liệu được kích hoạt. Tất cả dữ liểu chup mach MDĆT được chuyển đến trạm làm việc cho quá trình xử lý sau đó. Việc tái tạo hình ảnh được thực hiện trên các chương trình hình ảnh tướng phản tối đa (MIP), định dang lại đa măt phẳng (MPR) và tái tạo thể tích không gian 3 chiều (VR). Tiêu chí đánh giá động mạch thủ phạm trên chụp mạch MDCT theo Remy-Jardin (2004) [3].

- Quy trình chụp và gây tắc động mạch phế quản: Tiến hành với kim chọc động mạch 5-Fr (Terumo, Nhật Bản) thông qua đường động mạch đùi theo phương pháp Seldinger [4]. Chụp đồng mạch phế quản và động mạch không thuộc hệ phế quản chọn lọc theo kết quả chụp mạch MDCT trước đó. Gây tắc các động mạch bệnh lý theo Remy-Jardin (1974) [3].

- Xü lý số liệu: Phân tích thống kê sư dụng phần mềm SPSS 25.0 .

\section{KẾT QUẢ NGHIÊN CỨU VÀ BÀN LUÂN}

Từ ngày 01/09/2019 đến hết ngày 30/10/2020, có 22 bệnh nhân ho ra máu do lao phổi có chỉ định chụp mạch MDCT và gây tắc động mạch phế quản điều trị tại Bệnh viện Phổi Trung ương và Bệnh viện Quân y 103.

Bảng 1: So sánh kêt quả phát hiện động mạch thủ phạm trên chụp mạch MDCT và trong quá trình gây tắc động mạch phế quản

\begin{tabular}{|c|c|c|}
\hline Kết quả & $\begin{array}{c}\text { Số động } \\
\text { mạch }\end{array}$ & \% \\
\hline $\begin{array}{c}\text { Chụp mạch MDCT và gây tắc } \\
\text { ĐMPQ đều xác định là ĐM thù } \\
\text { phạm }\end{array}$ & 58 & 96,7 \\
\hline $\begin{array}{c}\text { Chụp mạch MDCT xác định ĐM } \\
\text { thủ phạm, gây tắc ĐMPQ xác } \\
\text { định bình thường }\end{array}$ & 1 & 1,65 \\
\hline $\begin{array}{c}\text { Chụp mạch MDCT xác định } \\
\text { bình thường, gây tắc ĐMPQ }\end{array}$ & 1 & 1,65 \\
\hline
\end{tabular}




\begin{tabular}{|c|c|c|}
\hline xác định ĐM thủ phạm & & \\
\hline Tổng & $\mathbf{6 0}$ & $\mathbf{1 0 0}$ \\
\hline
\end{tabular}

Chụp mạch MDCT phát hiện 59 động mạch bệnh lý, trong đó 1 động mạch được xác định là bình thường trong quá trình gây tắc ĐMPQ. Quá trình gây tắc ĐMPQ cũng phát hiện được 59 động mạch bệnh lý. Trong đó, 1 động mạch không phát hiện được trên chụp mạch MDCT. Vì vậy, tỷ lệ phát hiện động mạch bệnh lý chính xác của chụp mạch MDCT là 96,7\% (58/60). Tại Việt Nam, chưa có nghiên cứu nào so sánh kết quả phát hiện động mạch thủ phạm giữa 2 kỹ thuật này. Trên thế giới, theo nghiên cứu của Li (2019) tại Trung Quốc, nghiên cứu đâu tiên có nhóm chứng cho thây, tỷ lệ phát hiện động mạch thủ phạm ở nhóm được chụp mạch MDCT là $98,8 \%$ [6].

Bảng 2: Số lượng động mạch thủ phạm ở bệnh nhân nghiên cứu

\begin{tabular}{|c|c|c|}
\hline $\begin{array}{c}\text { Số động mạch } \\
\text { thử phạm }\end{array}$ & $\begin{array}{c}\text { Số bệnh } \\
\text { nhẩn }\end{array}$ & $\%$ \\
\hline 1 & 5 & 22,7 \\
\hline 2 & 8 & 36,4 \\
\hline 3 & 5 & 22,7 \\
\hline$\geq 4$ & 4 & 18,2 \\
\hline Tổng & $\mathbf{2 2}$ & $\mathbf{1 0 0}$ \\
\hline
\end{tabular}

Số bệnh nhân có 2 động mạch thủ phạm chiếm tỷ lệ cao nhất là $36,4 \%$. Số bệnh nhân có 1 và 3 động mạch thủ phạm là bằng nhau (22,7\%). Tỷ lệ bệnh nhân có $\geq 4$ động mạch thủ phạm là thấp nhất (18,2\%). Nghiên cứu của nhiều tác giả cho thấy trung bình có từ 1,8 - 2,1 động mạch thủ phạm trên một bệnh nhân. Bhalla (2015) báo cáo đã gây tắc tối đa 4 động mạch mỗi ca [7].

Bảng 3: Số động mạch thủ phạm trung bình trên một bểnh nhân

\begin{tabular}{|c|c|}
\hline Động mạch & $\begin{array}{c}\text { Số động mạch thủ } \\
\text { phạm/bệnh nhân }\end{array}$ \\
\hline ĐMPQ đúng chố & $1,3 \pm 0,53$ \\
\hline ĐMPQ lạc chố (biến thế) & $0,18 \pm 0,31$ \\
\hline $\begin{array}{c}\text { ĐM hệ thống không } \\
\text { thuộc hệ PQ }\end{array}$ & $1,02 \pm 0,97$ \\
\hline Tống & $\mathbf{2 , 4} \pm \mathbf{1 , 2}$ \\
\hline
\end{tabular}

Số động mạch phế quản đúng chố, ĐMPQ lạc chỗ và động mạch hệ thống không thuộc hệ phế quản trung bình trên một bệnh nhân lẩn lượt là $1,3 \pm 0,53 ; 0,18 \pm 0,31$ và $1,02 \pm 0,97$. Như vậy, tổng số động mạch bất thường trung bình trên mỗi bệnh nhân là $2,4 \pm 1,2$. So với nghiên cứu của Li [6], số lượng ĐMPQ lạc chỗ trung bình trên mối bệnh nhân trong nhóm MDCT cao hơn đáng kể so với nhóm chứng $(0,15 \pm 0,51$ so với $0,04 \pm 0,20, p=0,022)$. Không có sự khác biệt đáng kể nào về số lượng trung bình của các ĐMPQ đúng chỗ $(p=0,149)$ và ĐM hệ thống không thuộc hệ phế quản $(p=0,603)$ trên mỗi bệnh nhân giữa hai nhóm. Nghiên cứu của chúng tôi không có nhóm chứng, tuy nhiên, kết quả số động mạch phế quản lạc chố và ĐM hệ thống khổng thuộc hệ phế quản trung bình trên mỗi bệnh nhân của chúng tôi thậm chí còn cao hơn kết quả của tác giả này.

Bảng 4: Đường kính trung bình của các động mạch thủ phạm

\begin{tabular}{|c|c|c|}
\hline \multirow[b]{2}{*}{$\begin{array}{c}\text { Động mạch } \\
\text { bệnh lý }\end{array}$} & \multicolumn{2}{|c|}{ Đường kính trung bình } \\
\hline & $\begin{array}{c}\text { Khoảng dao } \\
\text { động(mm) }\end{array}$ & $\begin{array}{l}\text { Trung bình } \\
\text { (mm) }\end{array}$ \\
\hline ĐMPQ trái & $2,2-4,8$ & 3,0 \\
\hline ĐMPQ phải & $2,1-4,4$ & 2,8 \\
\hline Thân chung & $2,4-4,9$ & 3,1 \\
\hline Thân PQ-LS & $2,5-5,1$ & 3,3 \\
\hline
\end{tabular}

Đường kính động mạch phế quản lớn hơn $2 \mathrm{~mm}$ được coi là bất thường. Trong nghiên cứu của chúng tôi, đường kính các động mạch thủ phạm dao động từ 2,1-5,1mm, đường kính trung bình dao động từ 2,8-3,3mm. Theo hiểu biết của chúng tôi, hiện có hai nghiên cứu khác so sánh đường kính của các động mạch phễ quản thủ phạm được phát hiện trên MDCT với trên chụp mạch. Yoon (2005) nghiên cứu hồi cứu kết quả chụp mạch MDCT ở những bệnh nhân ho ra máu cho thấy đường kính của động mạch phế quản thủ phạm dao động từ 1,3 4,7mm (trung bình 2,8mm) [2]. Ngoài ra, 8 động mạch phế quản gây ho ra máu có kích thước < 2mm. Năm 2013, Gupta lần đâu tiên nghiên cứu tiến cứu chụp mạch MDCT ở bệnh nhân ho ra máu[8]. Kết quả thấy rằng đường kính của động mạch phế quản thủ phạm dao động từ 2,2 $5 \mathrm{~mm}$ (trung bình 2,9mm). Tuy nhiên, trong nghiên cứu của họ, giá trị điểm cắt $2 \mathrm{~mm}$ trên MDCT đã phát hiện tất cả các động mạch phễ quản bất thường phù hợp với phát hiện trên chụp mạch sau đó.

Bảng 5: Biến chứng sau chụp mạch MDCT ở bệnh nhân nghiên cứu (n=22)

\begin{tabular}{|c|c|c|}
\hline Biến chứng & $\mathbf{n}$ & $\mathbf{\%}$ \\
\hline Buồn nôn, nôn & 1 & 4,5 \\
\hline Dị ứng, nối mấn & 1 & 4,5 \\
\hline Sốc phản vệ & 0 & 0 \\
\hline
\end{tabular}

Buôn nôn, nôn và dị ứng, nổi mẩn là các biến chứng thường gặp sau chụp mạch MDCT với tỷ lệ 4,5\% (1/22). Không có trường hợp nào gặp sốc phản vệ. Nguyên nhân là do dị ứng với thuốc cản quang sử dụng trong quá trình chụp mạch MDCT. Kết quả này cũng là điều dễ hiểu do tính an toàn của chụp CT có tiêm thuốc cản quang 
đã được khẳng định từ lâu và trong thực tế kỹ thuật này đã được sử dụng một cách phổ biến.

\section{KẾT LUÂ̂N}

Chụp mạch MDCT ở bệnh nhân ho ra máu do lao phổi là một kỹ thuật an toàn, tỷ lệ phát hiện động mạch thủ pham cao (96,7\%). Các bệnh nhân chủ yếu có 2 động mạch thủ phạm $(36,4 \%)$, số động mạch trung bình trên mỗi bệnh nhân là $2,4 \pm 1,2$. Đường kính các động mạch dao động từ 2,1-5,1mm, trung bình 2,8-3,3mm.

\section{TÀI LIÊU THAM KHẢO}

1. World Health Organization (2019), Global tuberculosis report 2019 http:// www.who.int/tb/publications/global_report/en/.

2. Panda A., Bhalla A. S. and Goyal A. (2017), "Bronchial artery embolization in hemoptysis: a systematic review", Diagn Interv Radiol, 23(4), 307-317.

3. Remy-Jardin M., Bouaziz N., Dumont P. et al. (2004), "Bronchial and nonbronchial systemic arteries at multi-detector row CT angiography: comparison with conventional angiography", Radiology, 233(3), 741-9.

4. Bô̂ Y tê (2013), "Hướng dẫn Quy trình kỹ thuâtt Chẩn đoán hình ảnh và điện quang can thiệp", 859-862.

5. Remy J., Voisin C., Dupuis C. et al. (1974), "Treatment of hemoptysis by embolization of the systemic circulation", Ann Radiol (Paris), 17(1), 5-16.

6. Li P. J., Yu H., Wang Y. et al. (2019), "Multidetector computed tomography angiography prior to bronchial artery embolization helps detect culprit ectopic bronchial arteries and non-bronchial systemic arteries originating from subclavian and internal mammary arteries and improve hemoptysis-free early survival rate in patients with hemoptysis", Eur Radiol, 29(4), 1950-1958.

7. Bhalla A., Kandasamy D., Veedu P. et al. (2015), "A retrospective analysis of 334 cases of hemoptysis treated by bronchial artery embolization", Oman Med J, 30(2), 119-28.

8. Gupta M., Srivastava D. N., Seith A. et al. (2013), "Clinical impact of multidetector row computed tomography before bronchial artery embolization in patients with hemoptysis: a prospective study", Can Assoc Radiol J, 64(1), 61-73.

\section{TÁC DỰG CẢI THIÊ̂N HộI CHỨNG RẼ THẦN KINH THẮT LƯNG VÀ CHỨC NĂNG SINH HOẠT HÀNG NGÀY CỦA THỦY CHÂM THUỐC GOLVASKA TRÊN BỆNH ĐAU THẦN KINH HÔNG TO MẠN TÍNH}

\section{Lê Thị Hòe**, Nguyễn Thanh Thủy*, Đặng Kim Thanh*}

\section{TÓM TẮT}

Mục tiêu: Đánh giá tác dụng cải thiện hội chứng chèn ép rễ thần kinh thắt lưng và chức nắng sinh hoạt hang ngày của thủy châm thuốc Golvaska kết hợp điện châm và dùng bài thuốc Độc hoạt tang ký sinh trên bệnh nhân đau thần kinh hông to do thoái hóa cột sống và khảo sát tác dụng không mong muốn của phương pháp. Đối tượng và phương pháp: Nghiên cứu can thiệp, so sánh kết quả trước và sau điều trị, có đối chứng trên 60 bệnh nhân được chẩn đoán đau thần kinh hông to do thoái hóa cột sống. Kết quả: Nhóm 1 sử dụng Thủy châm Golvaska kết hợp điện châm và Độc hoạt tang kí sinh thang có chỉ số Lasègue trung bình tăng $27,97 \pm 14,23$ (đô) nhiều hơn nhóm 2 sử dụng điện châm và Độc hoạt tang kí sinh thang sau 15 ngày điều trị $(p<0,01)$. Nhóm 1 cải thiện chức năng sinh hoạt hàng ngày theo thang điểm Ówestry Disability tốt hơn nhóm $2(\mathrm{p}<0,01)$. Kết luận: Thủy châm thuốc Golvaska có tác dụng cải thiện hội chứng chèn ép rễ thần kinh và chức năng

\section{*Trường Đại học Y Hà Nôi \\ **Trung ương Hội đông y Việt Nam}

Chịu trách nhiệm chính: Nguyễn Thanh Thủy

Email: drthuy.yhct@hmu.edu.vn

Ngày nhận bài: 5.01.2021

Ngày phản biện khoa học: 4.3.2021

Ngày duyệt bài: 12.3.2021 sinh hoat hàng ngày ở bệnh nhân đau thần kinh hông to mạn tính và chưa thấy tác dụng không mong muốn của phương pháp.

Tư khóa: Đau thân kinh hông to, thủy châm, Golvaska.

\section{SUMMARY}

THE EFFECTS OF HYDRO - ACUPUNCTURE GOLVASKA ON IMPROVING LUMBAR NERVE ROOT ENTRAPMENT SYNDROME AND DAILY ACTIVITIES IN PATIENTS WITH CHRONIC SCIATICA

Objective: To evaluate the effects of hydro acupuncture Golvaska combined with electro acupuncture and Doc hoat tang ky sinh remedy on improving lumbar nerve root entrapment syndrome and daily activities in patients with chronic sciatica and side effects of the method on clinic and paraclinic. Methods: A prospective study, comparing before and after treatment, controlled on 60 patients diagnosed with chronic sciatica, type of degenerative lumbar spine according to traditional medicine. Results: The results showed that group 1 using hydro acupuncture Golvaska combined with electroacupuncture and Doc hoat tang ki sinh remedy had an average Lasègue score increased $27,97 \pm 14,23$ degrees, the level of reduction is higher than group 2 using electro-acupuncture and Doc hoat tang ki sinh remedy after 15 days of treatment $(p<0.05)$. Group 1 